\title{
Teacher Enrichment Initiatives: Supporting Teachers Who Are at the Frontline of Our Nation's Future
}

\author{
Chase W. Fordtran, Kandi K. Grimes, Rosemary A. Riggs, and Teresa M. Evans \\ Department of Pharmacology, UT Health San Antonio, San Antonio, Texas \\ Keywords: STEM Education, STEM Careers, Teachers, K-12 Education, Teacher Programs, Teacher Professional Development, Under-Represented \\ Student Populations \\ Publication Date: August 10, 2020 \\ DOI: https://doi.org/10.15695/jstem/v3i2.06
}

\begin{abstract}
Teachers are charged with connecting classroom science to real-world applications; however, opportunities for teachers to experience real-world applications in the life and biosciences are limited. When provided the opportunity to engage in hands-on learning experiences, teachers' capacity to connect classroom activities to real-world applications increases. Through partnerships within the local STEM Ecosystem, the Teacher Enrichment Initiatives (TEI) provides teachers with experiences that enable them to strengthen the connections between classroom science and careers. Over the course of TEI's 25+ years, these collaborations between our teachers and partners have resulted in the production of over 350 individual hands-on, inquiry-based curriculum activities. In addition, the TEI has played a pivotal role in the growth of the STEM workforce by disseminating best practices and providing teacher professional development (TPD) experiences designed to improve teacher knowledge of STEM career options and the associated educational pathways for their students while enhancing teacher professionalism. Since 2011, the TEI has hosted 15 TPD conferences and 300 workshops with over $1,800 \mathrm{~K}-12$ teachers participating annually. The number of students impacted through teacher participation exceeds 300,000 , covering all grade levels. To date, over 83 scientists, engineers, and STEM-career professionals have participated in TEI sponsored events.
\end{abstract}

\section{INTRODUCTION}

Over the past two decades the push for teachers to connect classroom science curriculum to real-world applications has significantly increased. This is in part due to the ever-growing need for a more robust science, technology, engineering, and mathematics (STEM) workforce. However, there are limited opportunities for teachers to experience real-world applications in the biosciences. For over 25 years the Teacher Enrichment Initiatives (TEI) has been providing teachers with professional development programs where they interact with scientists and members of the local STEM workforce to increase teacher awareness of current research and capacity to connect classroom activities to real-world applications.

Since 1997, the TEI has consistently been funded by the National Institute of Health (NIH) Science Education Partnership Awards (SEPA). Initially, the TEI created opportunities for clinicians to present to secondary science teachers. In these presentations, teachers learned about current research taking place at the University of Texas Health Sci- ence Center at San Antonio (UTHSA). As a result of these presentations, teachers generated innovative middle school curriculum transforming clinical language into age-appropriate activities. As the program evolved, the TEI became more responsive to teacher feedback in designing programs. This resulted in increased collaboration between scientists and teachers, producing 133 lessons comprised of over 350 individual hands-on, inquiry-based activities spanning elementary through high school (Figure 1).

In response to teacher feedback, the TEI has provided in-service teachers professional development opportunities, hosting 15 conferences and 300 individual workshops. Since the program began collecting robust data on attendance, over 1,800 teachers from all grade levels have participated in TEI-sponsored events, impacting over 300,000 area students. Over the past nine years 83 scientists, engineers, and STEM-career professionals have presented at TEI sponsored events, keeping teachers up to date on biomedical and 
Number of TEI Curriculum Materials Developed (1997-2019)

\begin{tabular}{|c|c|c|}
\hline Curriculum Units & \# of Lessons & \# of Activities \\
\hline Blood - Cast Your Net & 5 & 21 \\
\hline Bone Anatomy - Give Your Bones A Break & 5 & 26 \\
\hline Brain Anatomy - It's All in Your Mind & 7 & 29 \\
\hline $\begin{array}{l}\text { Cardiovascular System - Inflamm-O-Wars: Silent } \\
\text { Battles within Your Cardiovascular System }\end{array}$ & 5 & 17 \\
\hline Critical Thinking - Science Literacy & 26 & 25 \\
\hline Diabetes - Bittersweet: Diabetes & 7 & 16 \\
\hline Health Care - Healthcare, Why Should I Care? & 1 & 1 \\
\hline Idioms - Language and Aging - Embracing Diversity & 6 & 18 \\
\hline Intergenerational Relationships - My Older Friend & 6 & 17 \\
\hline $\begin{array}{l}\text { Levers in Human Body - Discrepant Design: Levers in } \\
\text { the Body }\end{array}$ & 1 & 3 \\
\hline $\begin{array}{l}\text { Media Evaluation - Analyzing Media Unit - Sequence } \\
\text { of Five Activities }\end{array}$ & 1 & 5 \\
\hline Mobility - Mo-bility: Movement by the Numbers & 4 & 18 \\
\hline Nutrition - You Are What You Eat & 6 & 15 \\
\hline Nutrition and Body Image - Nutrition and Aging & 4 & 12 \\
\hline Obesity Issues - Corpulosity: A Study of Obesity & 6 & 17 \\
\hline Ora Health - Watch Your Mouth & 6 & 28 \\
\hline $\begin{array}{l}\text { Research Organization - Foraging Fodder: Organizing } \\
\text { Research }\end{array}$ & 1 & 1 \\
\hline Population Demographics - Our Aging World & 6 & 15 \\
\hline Pulmonary System - Pulmo Park & 5 & 15 \\
\hline $\begin{array}{l}\text { Self-Assessment and Family Relationships - A Look } \\
\text { at Me }\end{array}$ & 5 & 13 \\
\hline Sleep Issues - ZZZZzzzWorld: Exploring Sleep & 7 & 14 \\
\hline Stereotypes and Biases - A Look at Them & 5 & 12 \\
\hline $\begin{array}{l}\text { Vision \& Hearing - Challenges and Changes: } \\
\text { Sensitivity to Vision \& Hearing Compromises }\end{array}$ & 8 & 19 \\
\hline Total: & 133 & 357 \\
\hline
\end{tabular}

Figure 1. TEI Curriculum Materials (1997-2019).

STEM-related advances. TEI has relied on robust quantitative and qualitative evaluation coupled with teacher feedback to inform the organizational evolution. By providing professional development training opportunities responsive to teacher identified needs, TEI helps teachers meet the needs of their students in an ever-changing educational landscape.

Our Roots. The teacher is the primary fulcrum for K-12 STEM education. Teacher effectiveness stands out as a key factor influencing quality education (Stronge and Hindman, 2003). The TEI journey to address the STEM needs of K-12 teachers in the San Antonio area began in 1994. The founding Principle Investigator, a gerontologist, assembled a small team which included the Director of the Barshop Institute for Longevity and Aging Studies and a local secondary science teacher with over 20 years of teaching experience.

Starting out, local funding supported the creation of 12 curricular units focused on science in the field of gerontology and health topics aligned with the educational research goals of the founding principal investigator. During this time the first iteration of TEI, entitled Positively Aging, was created. The TEI leadership was acutely aware of how more could be done to integrate gerontologic related science and health topics into science and mathematics curriculum. However, more funding was needed to sustain their vision, so they looked to the National Institutes of Health (NIH) Science Education Partnership Award (SEPA) for additional resources.

In 1993, a drive towards a more science-literate student population gained national traction with the release of the Benchmarks for Science Literacy report by the American Association for the Advancement of Science (AAAS). The project brought together 150 teachers and administrators to "help shape the future of America by providing recommendations on what students should know and be able to do in science, mathematics, and technology by the time they graduate high school." (AAAS, 1993). The report was a precursor to the No Child Left Behind (NCLB) legislation.

The TEI's first NIH SEPA grant entitled, Positively Aging - Phase I and Phase II, 1997-2000 and 2001-2003, was in part written to address the Benchmarks for Science Literacy report's recommendations. At the time, SEPA grants were structured in two phases of funding that ran consecutively. In accordance with the grant, TEI recruited teachers from the San Antonio area to participate in a six-week summer program to develop curriculum and attend presentations led by UTHSA faculty. The summer program provided the teachers with 180 Continuing Professional Education (CPE) hours. Teachers attended medical Grand Rounds presentations; however, teacher feedback about the presentations indicated a need for Teachers to have a deeper understanding of technical terms. The TEI Educational Development Specialist invited UTHSA researchers, scientists, and clinicians to engage with the Positively Aging teachers on a more approachable level. The curriculum created during the first summer program was a collaborative effort between teachers and UTHSA scientists and clinicians. Some of the themes covered in the curricular units were: Nutrition and Aging, Our Aging World, Give Your Bones A Break, and My Older Friend. Curriculum units such as My Older Friend contained activities promoting intergenerational learning activities between middle school students and elder daycare clients.

As the program expanded, additional needs regarding age-related health issues were identified by program teachers. To support these identified issues, the TEI secured additional NIH research grant funding through the National Center for Research Resources, National Institute for Dental and Craniofacial Research, National Institute on Aging, Minority K-12 Initiative for Teachers and Students, the National Heart, Lung, and Blood Institute, and the General Clinical Research Center to work in tandem with the SEPA Phase I and II grants.

During Phase II of the SEPA grant, TEI used the existing Positively Aging curriculum units as a scaffold to develop new instructional materials utilizing information from pa- 
tient-oriented clinical research. These curricular units effectively taught scientific and mathematical concepts, such as force and motion, through mobility, obesity, disease, and healthy living across the life span. Public school curriculum was, and still is, a crowded field and the introduction of supplemental teaching materials not mandated by the State of Texas or school districts remains an on-going challenge. To meet this challenge, program teachers aligned curricular units with the Texas Essential Knowledge and Skills (TEKS). The TEKS standards outline what students in Texas schools should learn in each course or grade.

The Positively Aging workshops and trainings encouraged teamwork and the adaptation of lessons and activities to address each teachers' unique classroom dynamics. Workshops were held each summer (2000-2002) for K-12 science and health teachers. These full-day workshops ranged from one to two weeks, with teachers receiving 30 to 60 continuing professional education credits (CPEs). During the workshops, teachers were introduced to various classroom applications of the Positively Aging curriculum and free resources available on the Positively Aging website. The workshops provided an opportunity for UTHSA researchers and health professionals to present their research which corresponded to the TEI health and aging curricular units.

The Influence of Evolving Technologies and Education Policy on Teacher Engagement. By 2001, the TEI had expanded the program's website and created a cohesive set of quantitative evaluation strategies to assess the dissemination and implementation of the Positively Aging teaching materials within area classrooms. As TEI expanded their website presence, the program questioned how teachers would use resources available through the website since the technology was novel to area classrooms. TEI partnered with four middle schools in a three-year pilot study that would be used for internal purposes. The internal pilot study investigated the optimal dissemination of the TEI's curricular materials. In the pilot study, the control group only had electronic support from TEI, in the form of email and website access. The intervention group had the same electronic access but also received face-to-face support from the TEI EDSs. Website and classroom utilization of lessons were actively tracked during the internal pilot study. Teachers from all four schools were eligible and invited to participate in the TEI's summer training program (Stealth Gerontology ${ }^{\mathrm{TM}}$ Workshops) to learn about the teaching materials and how to utilize the website (Pruski et.al., 2004). Due to yearly teacher turnover and new teacher hires in the four study schools, the number of participants involved in the pilot study varied. There were 374 participating teachers by the third and final year of the study.

The pilot study teachers saw the potential in Positively Aging materials to provide lessons that would develop the content knowledge and problem-solving skills necessary for students to do well on the Texas Assessment of Knowledge and Skills (TAKS). The TAKS was the standardized test used by the state of Texas at the time of the SEPA grant. It covered a number of school subjects and assessed skills required under Texas education standards. The pilot study teachers encouraged revisions to the website so that activities were more interactive and the website was more accessible. The website originally required a log-in with a password, and the study teachers found that this was enough of an inconvenience to discourage utilization of the teaching materials.

Classroom use of materials increased during the study and the interaction between the schools during the year of the study was statistically significant, see Figure 2 . However, this study demonstrated that in-school support by TEI staff was advantageous to disseminate the Positively Aging teaching materials. Potential dissemination barriers included competition for instructional time with district implemented curricular content, variability in teacher's computer literacy, teacher and student turnover, and the time constraints associated with the introduction of federally mandated standardized testing.

During the SEPA Phase II funding cycle, the No Child Left Behind (NCLB) Act took effect. NCLB marked a historic expansion and alteration of the federal government's role in K-12 education policy. The policy mandated "all students demonstrate proficiency in all state grade-level standards reading, writing, and mathematics by 2014" (McCullers and Bozeman, 2010, p. 54). According to McCullers and Bozeman, this policy was essentially "a top-down approach to educational governance" (p. 54). A complex system of annual benchmarks were put in place to hold individual schools accountable with testing outcomes impacting funding for Title I schools. This put pressure on teachers throughout the United States to raise student achievement to unachievable levels (Ladd, 2017). Knepper (2009) posits these mandates would result in lowering academic standards to meet minimum requirements "historically failing schools falling further behind as a result of NCLB's unreachable goals" (p.

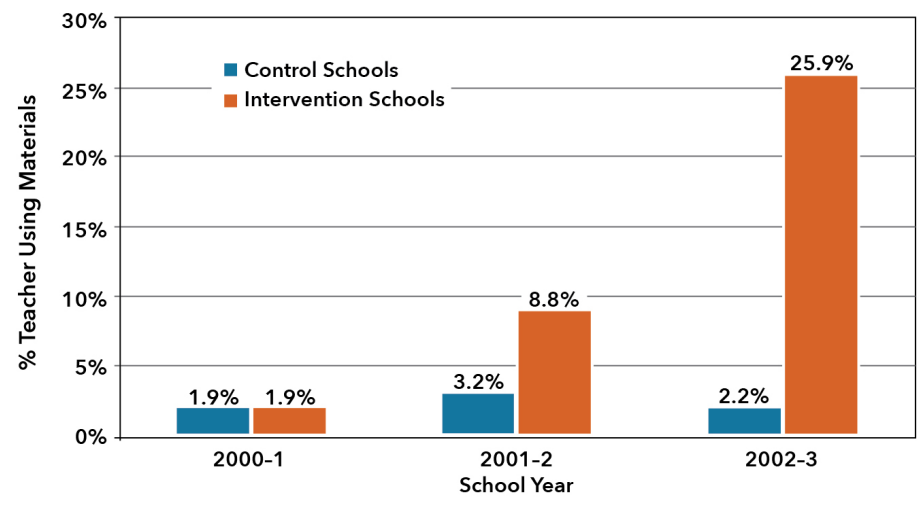

Figure 2. Teacher Utilization of Positively Aging Teaching Materials, Note: 2000 - 2003 SEPA Positively Aging - Phase II pilot study. Materials used for the study included twelve units of Positively Aging ${ }^{\circledR}$ teaching materials (276 activities). 
901). Even congressional staff recognized that there was no way to reach NCLB's 100\% proficiency goal (McCullers and Bozeman, 2010).

Teachers were mandated to follow an essentially static curriculum that limited teachers' ability to introduce external curricular materials, which caused a rigidity in their teaching abilities (Whitney, 2017). A teacher involved with a study by The Civil Rights Project at Harvard University, stated, "NCLB has become so much the instructional focus that ... needed enrichment experiences are not planned or eliminated because they are not tested" (as cited in Knepper, 2009, p. 915). The implementation of NCLB caused TEI to reassess their program which guided their program evolution.

In 2003, SEPA discontinued the two-phase grant model, consolidating Phase I and II into a five-year funding structure. It was at this time that TEI received its second round of funding through SEPA entitled, Positively Aging: Optimizing Mobility across the Lifespan, 2003-2008. During this SEPA grant, TEI wanted to address some of the challenges in the educational system that NCLB was causing. Speaking with TEI teachers it was clear that they felt they had lost their autonomy and latitude to bring in lessons and activities they regarded as important to students. To provide teachers leverage to use TEI curriculum in their classrooms, aligning the activities with the Texas Essential Knowledge and Skills (TEKS) became a top priority. The TEKS standards outline what students in Texas schools should learn in each course or grade. This gave teachers the ability to incorporate and adapt their innovative teaching materials while still satisfying school and state-mandated goals. In 2003, the program was awarded two additional grants through the National Heart, Lung, and Blood Institute (NHLBI) and the National Center for Research Resources (NCRR). The NHLBI grant covered science education with a focus on cardiovascular health. The NCRR grant focused on obesity and maintaining mobility across the life span.

With the additional grants, their summer teacher intensive program included the six SEPA teachers, five NHLBI teachers, and five NCRR teachers. Each group of teachers worked on the specific aims of their grant. However, they blocked in time for the teachers to interact in a synergistic manner, sharing their learned experiences and exchanging ideas. These 16 teachers represented 14 schools and six school districts located in Bexar County and Medina County. These schools had a majority-minority student population which are traditionally under-represented in science. At that time, the student population of these 14 schools was $81 \%$ Hispanic and 3\% African Americans. These student populations were also classified as socio-economically disadvantaged based on qualification for free or reduced lunch $(72 \%)$.

The TEI summer teacher training experience was called INQUIRE (Inquiring, Networking, Questioning, Understanding, Involving, Researching, Evolving). In preparation for the summer teacher program TEI staff collected literature and other resources to support their teachers in the development of new lessons. Utilizing the program's existing partnerships, TEI staff and leadership worked with scientists at UTHSA and created six new curricular units with a total of 36 classroom activities. These units include Mo-bility: Movement by the Numbers, Zzzzz World: Exploring Sleep, Inflamm-0-Wars: Silent Battles within Your Cardiovascular System, Corpulosity: A Study of Obesity, Pulmo Park: Pulmonary Adventures, and Health-Related Career Exploration. TEI applied and were approved for two trademarks associated with their teacher resources, a three-dimensional (3D) food pyramid and the Fat Minder, a teaching aid that will help teach students about mass, volume, and energy balance. These curricular units remain on the website, TEIteachers. org/units, free to download.

At the beginning of the 2004-2005 school year, TEI collected data from over 3000 middle school students regarding attitudes toward science using six validated scales. These scales included Women in Science Scale (WISS), Images of Science and Scientists Scale (ISSS), Science Attitude Inventory (SAI), Simpson Troost Attitudes Questionnaire (STAQ), Test of Science Related Attitudes (TOSRA), and Draw a Scientist Scale (DAST). After reevaluating the psychometric properties of these instruments in student populations, the analysis showed that the factor structures did not match the original authors' claims. In turn, the program produced a comprehensive review of the 65 science attitude scales that appeared in peer-reviewed publications between 1935 and 2005. Their findings were published in the International Journal of Science Education. This review of science attitude scales demonstrated that psychometric evidence of the validity of these types of instruments is often lacking in clarity and function (Blalock et al., 2008). Several items from these instruments that did not fit the factor structures were removed. These shortened instruments with improved psychometric properties would prove to be more feasible for researchers and administrators. TEI used this information to select the most robust scales to incorporate as outcome measures in future studies.

One of TEI's SEPA aims was to assess student attitudes toward science. From the team's previous research into validated scales, they had identified the Simpson Troost Attitude Questionnaire-Revised (STAQ-R) as the instrument best suited for the study. TEI staff recruited 15 teachers from eight schools in seven school districts to test their Positively Aging lessons using pre- and posttests during the 2007-2008 school year. A total of 1,515 students in the sixth, seventh, and eighth grades were included in the pre- and posttest. Although there were gains in knowledge specific to the activities, the pre- and posttest highlighted the challenges in collecting this type of data in classrooms. As in previous studies, it was challenging for teachers to use classroom time 
to collect data due to competition for instructional time with other curricular content and the effects of mandatory testing on the educational process. If a teacher was not fully trained or had not thoroughly reviewed the lessons, their ability to deliver the content effectively was impacted. The receptivity of students to the curriculum varied widely and there was a correlation between receptivity and student abilities.

From the STAQ-R data, TEI leadership concluded there was a need to provide teacher professional development training beyond the current summer programs for teachers to increase their proficiency and familiarity with the curriculum. TEI needed to improve the ease of accessibility to increase dissemination of their products to teachers at a local and national level. One way of improving accessibility of the program's teaching materials was to broaden the TEI website's function which aligned with the program's SEPA grant's aims. With the help of a hired Graphics Specialist and a web developer, the TEI's website expanded to include the new curriculum created during their grant period in downloadable electronic format Portable Document Format (PDF). Previous versions of the website were restricted by a required account login and completion of a survey. The newest iteration of the program's website allowed anyone, at the local, national, and global level, to download the program's teaching materials. Between 2006 and 2007 the total views of the website, TeachHealthK-12.uthscsa.edu, now TEIteachers.org, grew to 60,000 views per month. At the time, the website was the third most visited site in the UTHSA's domain.

The teachers began their fourth summer of work at the UTHSA campus on June 4, 2007. The funding from the SEPA and NCRR grants enabled TEI to recruit 23 teachers for the fourth summer teacher program. These 23 teachers represented 16 schools and nine school districts in Atascosa, Bexar, and Medina Counties. Fourteen of the original teachers stayed with the program for five years, which is an incredible retention rate and shows the benefits of the training programs. By 2008, the program entered its final year of Positively Aging: Optimizing Mobility across the Lifespan. TEI program staff had grown to six highly qualified individuals that produced and published 16 research articles in peer-reviewed journals. Teachers continued to work with TEI staff and UTHSA scientists to create, disseminate, and evaluate new teaching materials based on examples from geriatrics and gerontology. Taking into consideration data from the STAQ-R study, teachers began revision work on the existing curricula in response to experiences in classroom utilization.

During the final year of the Positively Aging: Optimizing Mobility Across Life grant, TEI submitted and received a no-cost extension for 2009. This funding extension gave the program an opportunity to seek additional funding sources and explore different educational opportunities. They leveraged their time to submit three additional multi-year grants through NIH supported programs. These grants enabled them to continue their mission of curriculum development, improving teachers' knowledge skills and confidence levels through TPD workshops and summer programs, ultimately impacting their students.

When developing the aims for the three new grants, the TEI had to keep in mind the ever-changing educational landscape occurring in the US at the time. In 2007, the National Academies (NA) was congressionally tasked to create a report that addressed the ever-increasing erosion of high-quality U.S. jobs in the science and technology sectors within the world marketplace. The National Academies include the National Academy of Sciences, National Academies of Sciences, Engineering, and Medicine, the National Academy of Engineering, and the National Academy of Medicine. The NA are a private, non-profit society of distinguished scholars.

Pre-eminent members of the NA formed committees to address the following question: "What are the top 10 actions, in priority order, that federal policymakers could take to enhance the science and technology enterprise so that the United States can successfully compete, prosper, and be secure in the global community...?" (The National Academies, 2009). Their answer to this question was published in the report, "Rising Above the Gathering Storm". Their recommendations included a need to strengthen the skills of teachers through training and education programs at summer institutes. The training would need to enhance a teacher's knowledge in the fields of science, technology, and mathematics. (The National Academies, 2007). The report also summarized that the improvement of K-12 science and math education through teaching practices would vastly improve the talent pool of highly qualified individuals in the United States. The report bolstered the need for STEM-related subject knowledge to be a focus in K-12 education. These key recommendations related directly to what the TEI program was trying to accomplish.

The report linked the improvements to student achievements with teacher excellence and pointed out a lack of qualified teachers with certifications or degrees in the subject matter they taught. This is especially critical when it came to science and mathematics (The National Academies, 2007). The need to retain and empower highly qualified K-12 educators were identified as key to the success of our country's future. TEI hoped to tackle some of these recommendations with their upcoming grants.

In response to the recommendations in Rising Above the Gathering Storm, TEI expanded their mission to include aging, neuroscience education, and community handbook to promote science literacy. They were awarded their third consecutive SEPA grant entitled, Positively Aging: Maximizing the Healthspan (MAX), 2009-2014. At the same time, They were awarded a National Institutes of Health (NIH), 
Science Education Drug Abuse Partnership Award Program grant entitled, Critical Appraisal to Improve Neuroscience Education (CAINE), 2009-2013, to transform journal articles about drug addiction and the brain into age-appropriate activities. Finally, the TEI was awarded an Institute for Integration of Medicine and Science (IIMS) grant, 2009-2011, to generate an informative community health manual.

The CAINE, MAX, IIMS teachers participated in 180 hours of professional development during their respective summer programs as recommended by the National Academies' recommendations. The MAX project produced two comprehensive curricular units based on the following articles: "Rapamycin fed late in life extends lifespan in genetically heterogeneous mice" (Harrison, et al., 2009) and "Association of long-distance corridor walk performance with mortality, cardiovascular disease, mobility limitation, and disability." (Newman, 2010). Changes in mandated summer training for teachers interfered with TEI teacher recruitment as schools and districts implemented their own required summer teacher professional development (TPD). As a result, typical recruitment and randomization were not possible. In response to these unexpected changes, the TEI opted to create a non-randomized study. As a result, CAINE had four intervention teachers and four control teachers for the 2010-2011 school year. TEI treated the first year as a pilot year which allowed them time to develop a randomized/control recruitment mechanism for the remainder of the grant that would not interfere with summer TPD programs mandated by area schools and school districts.

Over the course of the CAINE program, it established partnerships with 19 neuroscience and other researchers from UTHSA and the University of Texas San Antonio (UTSA), and produced five transformed articles centered on epigenetic effects of cocaine, dopamine and risk-taking behavior, topiramate and alcoholism, and a review article summarizing over 77 studies about the addiction process. The TEI disseminated these curricular materials through their website, teacher workshops, presentations at educational and scientific meetings, publications in peer-reviewed journals, and community engagement through the national Clinical and Translational Science Award consortium.

During the CAINE and MAX projects, the TEI investigated the impact of their in-depth teacher professional development on middle school students' attitudes toward science through the STAQ-R and WISS-R. The WISS-R was administered to a total of 2,047 middle school students (6 grade- 8 grade). After the first year of using the WISS-R no significant differences among middle school student attitudes toward women in science had emerged. Given that the WISS-R did not change over the school year, the TEI decided to abandon its use. This reduced the data collection burden for the teachers.

We successfully used the STAQ-R to measure changes in student attitudes in the study of In-Depth Teacher Professional Development (TPD) (Intervention: $\mathrm{N}=6$ teachers) vs. usual TPD (Control: $N=6$ teachers). Over each of three school years, students of comprehensive TPD teachers had significant improvements (compared to students of control teachers) on the three STAQ-R subscales where teachers have influence: 'Motivating Science Class' $(\mathrm{p}<0.001)$, 'Science is Fun for Me,' $(p=0.007)$ and 'Self-Directed Effort' $(p=0.032)$. The effect sizes were $10 \%, 7 \%$, and $11 \%$ respectively for the subscales.

In 2010 the TEI tested the Self-Efficacy Teaching and Knowledge Instrument for Science Teachers-Revised (SETAKIST-R) at a national teacher conference. The SETAKIST-R was designed to assess the self-efficacy of science teachers. At the conference, $334 \mathrm{~K}-12$ science teachers completed the SETAKIST-R. However, the SETAKIST-R proved not to be robust enough and the program did not utilize it any further. They published their study entitled, "Construct Validation of the Self-Efficacy Teaching and Knowledge Instrument for Science Teachers-Revised (SETAKIST-R): Lessons Learned" (Pruski et al., 2013). More promise was seen in other scales, such as the STEBI, to track teacher self-efficacy in their TPD programs.

Through Clinical and Translational Science Awards, the IIMS program partnered with UTHSA, the South-Central Area Health Education Center, and Texas Biomedical Research Institute (Texas Biomed), home of the Southwest National Primate Research Center. The IIMS teachers toured labs, clinics, animal facilities and attended lectures at both of Texas Biomed's Institutional campuses. IIMS teachers also developed a manual entitled, Promoting a Healthier Community: Bringing About Change - A Handbook for Community Health. The teachers in the IIMS program revised teaching materials to better align with evolving state standardized tests.

The Importance of a Teacher Academy and Teacher Professional Development Opportunities. Soon after the MAX, CAINE, and IIMS grants were awarded, TEI endeavored to reach more teachers. The TEI saw the need for a teacher-led network of empowered in-service teachers who could collaborate year-round to improve bioscience and health education in the San Antonio area in the form of a teacher academy. Using a "grass-roots" approach, the teacher-led academy would improve math, science, and health education by disseminating best practices and providing STEM-focused TPD. In 2010, the TEI received the funding to make this happen, through a local foundation, the Max and Minnie Tomerlin Voelcker Fund. This local, private foundation provides support for medical research and educational organizations. The Voelcker funds (2010-2013) were used to develop a teacher academy, called the Voelcker Biosciences Teacher Academy (VBTA). The development process of the 
VBTA started on October 23, 2010, at the VBTA's inaugural annual business meeting (Fall TEAM UP Meeting). It was attended by 37 local teachers, the TEI staff, and a professional facilitator.

The guiding question for the meeting was: How can the TEI build the VBTA into a powerful body that leads, inspires, and supports improvements in math, science, and health education in Bexar and surrounding counties? With the help of the facilitator, the teachers set key priorities for the first year of the academy and set future goals. It was decided that quantitative and qualitative data collected at designated VBTA TPD events would guide the academy's evolution. The main goals set during the Fall TEAM UP Meeting were engaging the teacher community through an annual professional development dissemination conference in the spring, creating a web-based professional network through a VBTA website and social media (i.e., Facebook and Twitter), give recognition for teaching excellence through a teacher of the year award, and remarket resources that provide current curricular materials that are based on student-centered learning.

There were five teacher leaders recruited for the VBTA's first summer program. The summer program started on June 14, 2011, and ran alongside the MAX, CAINE, and IIMS summer teacher programs. The five VBTA teacher leaders networked with the other summer program teachers to disseminate any new materials or ideas. During this first summer, the VBTA teachers partnered up with UT Health scientists to help develop and revise existing TEI activities with a focus on Voelcker Fund health priorities: arthritis, cancer, heart disease, muscular dystrophy, and macular degeneration. The teachers laid out a framework for the first annual dissemination spring conference. The conference was held on Saturday, March 5, 2011, and the chosen theme for the first conference was To the STAARS and Beyond, in reference to the State of Texas Assessments of Academic Readiness (STAAR). The conference hosted 128 teachers and featured workshops presented by local teachers and scientists from UTHSA, Texas A\&M Vet School, and the Georgia Institute of Technology. It provided teachers with networking opportunities, hands-on make-and-takes, workshops featuring TEI curriculum, six Continuing Professional Education (CPE) hours, and free breakfast and lunch. At the conference, TEI collected quantitative and qualitative data from workshop surveys to help guide the evolution of the Spring Conference and the VBTA program.

During the summer, VBTA teacher leaders worked with the TEI Educational Development Specialist and Graphic Specialist to create a stand-alone VBTA website. The website was used to promote the second Fall TEAM UP Meeting, second Spring Conference, additional TPD opportunities, and housed a repository of VBTA curated teacher resource links. The TEI website (teiteachers.org/teacher-academy) linked directly to the teacher academy website and vice ver- sa to increase total page views and dissemination of program information. In addition to the website, a VBTA Facebook page (facebook.com/telateachers) and Twitter (twitter.com/ telateachers) account were created. The teacher academy's Facebook account currently has over 420 engaged local K-12 teachers and the Twitter page exceeds 500 followers. Both of these social media outlets have been utilized successfully over the past eight years to disseminate VBTA materials and TPD event opportunities.

On February 25, 2012, the second annual Spring Conference took place on the UTHSA campus, its theme was Bridge to the STAARS. The STAARS theme continued into the second year because the pressures of reaching unattainable achievement goals through the state's standardized tests were still high for local teachers. The VBTA conference brought together TPD experiences that allow teachers to creatively address state standards as "high-stakes testing often causes educators to lose sight of meaningful and creative science instruction" (Longo, 2010). Attendance levels for the conference grew to 148 teachers. New that year, the VBTA added exhibitors and hosted a nationally renowned author as its keynote speaker for the conference, Elva Treviño Hart, who shared her book The Barefoot Heart: Stories of a Migrant Child. Workshop topics such as Elementary Nano Technology and Exploring the Science TEKS were included in the TPD workshop offerings. Local teachers and scientists along with representatives from the Texas Education Agency (TEA) participated as TPD workshop presenters.

The VBTA program had made substantive progress during the first few years of Voelcker funding, but engagement within the teacher community and facilitating a culture change requires time and investment to forge sustainable programs. TEI requested three more years of support to continue VBTA development and achieve sustainability. In 2013, TEI received a second award from the Max and Minnie Voelcker Fund, 2013-2016. The VBTA teacher leaders continued their yearly six-week summer teacher professional development program to build experience with curriculum development and evaluation, increase their scientific knowledge, and improve their pedagogical skills. The VBTA teacher leaders assumed greater leadership roles within the academy, drafting bylaws and a mission statement, and served as the voice of area teachers in developing programs. There are limited leadership opportunities for teaches within their school community and the VBTA provides teachers with leadership training. Leadership is key to developing a long-lasting adult learning community. (Drago-Stevenson and Pinto, 2009).

In February of 2013, the third annual Spring Conference, themed as Universe of Possibilities, was held and the number of attendees grew to 158. As the Spring Conference grew, it became apparent one day of TPD was not sufficient to meet the growing requests from area teachers. As a result, 
the VBTA introduced Coffee, Collegiality, and Collaboration (C3) in the summer of 2013. The C3 Workshops were held monthly during the school year and weekly throughout the summer. Between 2013-2015, the C3 Program grew from three workshops (2013) with 34 teachers attending to 19 workshops (2015) with 476 participants. Topics included specific science content (genetics, diabetes, stem cell research), pedagogical approaches (flipped classrooms, inquiry, hands-on activities), and locating classroom resources (identifying area resources, grant writing support).

In 2014, the TEI's third SEPA grant came to an end. During the course of the MAX SEPA grant, the TEI was able to show that students of teachers who engaged with in-depth TPD demonstrated statistically significant improvements in three STAQ-R Subscales compared to students of teachers engaged in their usual professional development. The TEI also provided TPD programs over three summers, which gave their teachers the chance to earn $180 \mathrm{CPE}$ hours per summer. In addition, the TEI program's teachers transformed and produced curricular units based on peer-reviewed articles.

The TEI team prepared for a new SEPA proposal that would fund in 2016. The group's aims directly related to sustaining the teacher academy. In the meantime, the 2014 Spring Conference themed as Science: The Incredible Journey had a $17 \%$ attendance increase from 2013. Of the 28 workshops offered, $43 \%$ were conducted by VBTA teacher members. Teachers from 29 area school districts, including private and charter schools posted a 20\% increase in districts present. Grade level distribution was reasonably even (36\% elementary, 30\% middle school, 34\% high school). The resulting impact of the professional development provided to the 169 teachers in attendance reached nearly 19,588 students. The teacher attendees provided robust feedback from the conference's workshop surveys to guide the following year's event. As for keynote speakers, the TEI hosted a former president of the National Science Teachers Association (NSTA) for the opening keynote presentation and for the closing session, the TEI had a hands-on presentation by a global educator.

Through their storied past TEI has realized the significant value of partnerships. In the fall of 2014, the VBTA started collaborating with the Office of Career Development (OCD), which was founded and directed by a faculty member at UTHSA who is now TEI's Principal Investigator. The OCD provides comprehensive career and professional development programming to graduate trainees at the UTHSA. It was noted by the OCD and TEI staff that there was a lack of training in communication for postdoc and graduate trainees as well as a lack of knowledge of science and STEM-related careers in the local community. So, TEI created a bridge between graduate education and the community through K-12 teachers. The collaboration resulted in the sponsoring of Science Nights at area schools and provided postdocs and graduate trainees opportunities to present to area teachers during TPD workshops. It established sustainable networks between postdocs/graduate trainees and area teachers.

Using these networks, postdocs and graduate trainees strengthened VBTA's teacher science content knowledge while learning effective pedagogical approaches from teachers (Figure 3). One of the VBTA teacher leaders commented about the experience, "collaboration between the VBTA and OCD has benefited my students and colleagues beyond words. Presentations by postdocs and graduate students at VBTA workshops connect me to the latest science research, which enables me to keep my science lessons current." A sample of the workshop topics that the trainees covered were "Ebola Virus: The Biology, Epidemiology, and Sociology"; "Sci $\neg$ ence Methods and Science Careers"; "Ditching the Pea Plants: Teaching Genetics for a New Generation"; and "Scientist Meets Science Teachers: Career Path of a Translational Scientist".

The fifth annual VBTA Spring Conference, Closing the Synaptic Gap, was held February 7, 2015, at the UTHSA main campus. The conference had a total attendance of 219 ,

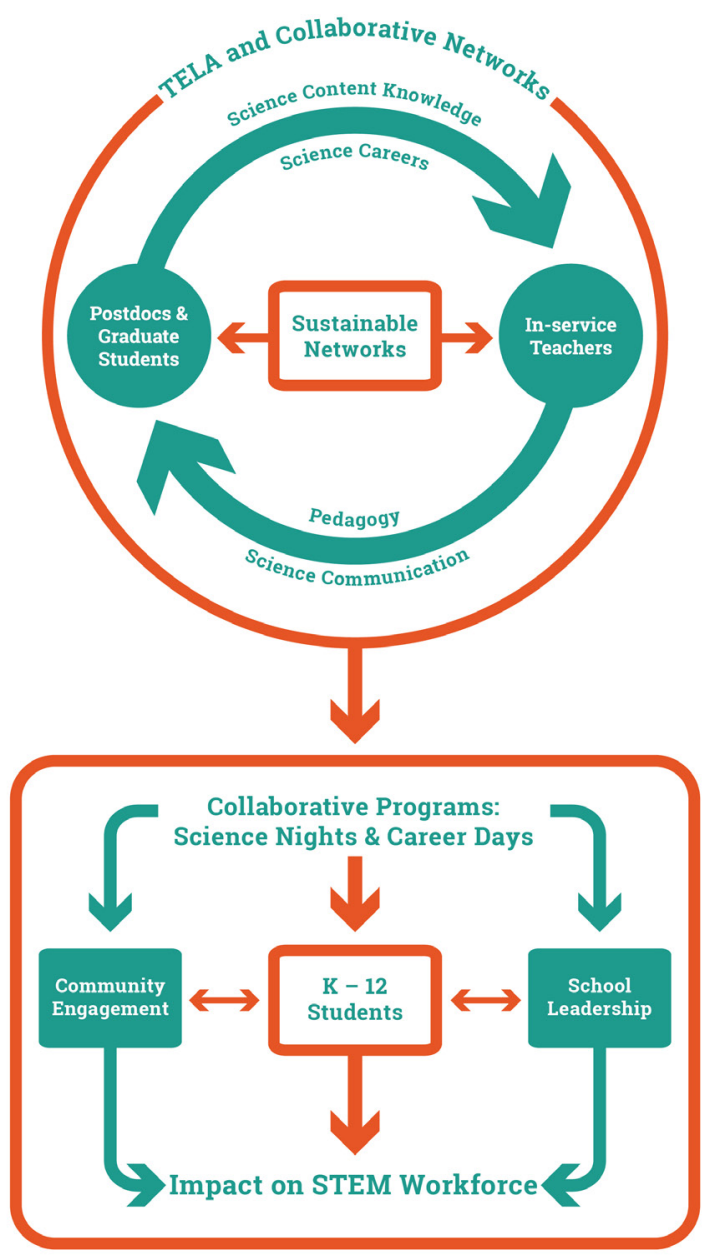

Figure 3. Collaborative Relationship Between TELA and UT Health San Antonio Graduate Students. 
which included 192 teachers (174 teacher participants and 18 teacher presenters) and 27 presenters from area universities, research facilities, and local agencies. Teachers from 33 area school districts attended the event. Of the 19 school districts located within Bexar County, 13 districts were represented at the conference. Since the VBTA Spring Conference began in 2011, the number of districts in attendance has increased by $230 \%$. Compared to 2014, the 2015 conference posted a $20 \%$ attendance increase. Since the spring conference's inception in 2011, attendance has steadily increased by $71 \%$ showing the ever-growing need for quality TPD training.

The 2015 Spring Conference attendees were asked to respond to three of the VBTA's aims for the upcoming year: Science Nights, Grant Writing, and Mentoring/Networking. A sample of the responses showed that $52.5 \%$ of teachers stated their schools did not offer science nights and $97 \%$, believed that a science night at their school would benefit students. Regarding grant writing, $88 \%$ of the teachers had not previously applied for grants. As to the reasons given, 78.8\% believed grant writing was an overwhelming task and 70\% of the teachers believed they did not have the time to pursue a grant. However, if support from experienced grant writers were available, $88.3 \%$ would be willing to apply for a grant. A majority of the teachers were interested in learning more about grants $(85.9 \%)$ and are willing to attend a grant writing workshop $(79.4 \%)$. Of the teachers at the conference, $45.9 \%$ had served as official mentors for other teachers at their school. However, only $29.7 \%$ received mentor training from their school or district. Feedback from the teachers indicated they would benefit from peer-mentoring training $(87.3 \%)$ and were willing to participate in a teacher professional networking and mentoring program $(82.9 \%)$.

Despite efforts to make school districts accountable through NCLB legislation, the top-down approach did not see improvement in secondary educational outcomes. The TEI had tried to remedy this issue through hands-on inquiry-based curriculum and in-depth TPD training. In-service teachers had become de-professionalized and were expected to present science content in a "lock-step" fashion throughout the school year. This resulted in a demoralized group of teachers. It made it difficult to retain qualified K-12 educators. In turn, many students did not enter into the STEM workforce after high school. The national committee (CoSTEM) put out a call to tackle this ever-growing problem by declaring the need to "prepare 100,000 excellent new K-12 STEM teachers by 2020 and support the existing STEM teacher workforce."

The TEI's new SEPA grant entitled, Empowering K-12 STEM Teachers Through a Bioscience Academy, 20162019, directly answered these issues through its aims of peer mentoring, community engagement through science nights, and grant writing. Using the 2015 Spring Conference feedback data the TEI's newly entitled Teacher Enrichment
Leadership Academy (TELA) started three Teacher Leader led committees that addressed the above mentioned SEPA aims. During the 2017 TEAM UP meeting the TELA teacher leaders presented training materials they had developed over the 2016 and 2017 teacher summer program. These materials covered the aims of Peer Mentoring, Community Engagement, and Grant Writing. They presented these training materials to a small engaged group of TELA teacher members. The TEAM UP meeting provided necessary feedback to strengthen the training before implementing it on a larger scale.

The Texas State Board of Education (SBOE) administrative code requires teachers with two or fewer years of teaching experience are required to have an experienced teacher mentor within the same subject or grade level (SBOE, Sec.21.458). According to the code a teacher mentor must complete a research-based mentor training program. To fulfill the requirements of the mentor code the TELA created a Peer Mentoring training that consists of three 90-minute modules: Module 1: Establishing and Sustaining Professional Relationships, Module 2: Transformative Mentoring and Professional Growth, and Module 3: Creating Professional and Personal Balance. The inaugural training was held during the annual TEAM UP meeting on October 13, 2018, with 23 teachers participating. At the end of the training, participants completed a retrospective evaluation allowing participants to assess their degree of knowledge or skill prior to attending the training and afterward. Teachers also completed a survey to provide feedback about the training. In each of the 12 topic areas covered in the training, teachers indicated knowledge gains. Teachers generally disagreed with statements of understanding before the training but agreed or strongly agreed by the training's end.

Using the data from October training workshop, a modified mentor training workshop was conducted at the annual 2019 TELA conference. Fourteen participants (seven high school teachers, five middle school teachers, one elementary teacher, and three administrators) attended the training. The workshop utilized the content based on the areas from the initial training that showed the most growth: roles and responsibilities of mentors, differences between andragogy and pedagogy (how and why adults learn as compared to how and why children learn), application of adult learning theories to mentoring and to collegial interactions. The workshop used the Module two retrospective evaluation. The largest knowledge gains were consistent with those from the October training workshop: andragogy vs. pedagogy (50\% growth), transformative learning (40\% growth), and applying constructivist theory to adults (30\% growth).

To aid in the development of science nights, the TELA leaders and TEI staff created planning tools, hosted TEI booths, and held science night training workshops featuring TEI activities. In the summer of 2019, the TELA leaders up- 
dated the science night training PowerPoint and made it into a narrated video training module available through the TEI website resources page. Some of the science night tools TEI created were a Needs Assessment/Identifying Objective, Planning Checklist, and Science Night Evaluation Protocol. During 2017-2019 school years the TEI/TELA participated in 14 science nights that involved an average of 300 attendees per event. In 2019 the TEI began a partnership with the Mind Science Foundation (MSF). The MSF is a San Antonio area organization that funds innovative research and accessible educational programs focused on the mind, brain and human consciousness. The MSF provided volunteers and supplementary educational materials for four of the TEI's science night booths.

The TEI utilized the Science Night Observation Protocol to evaluate science night activities and engagement of parents with students. Using the observation protocol, TEI conducted a case study with a local elementary school over a three-year period. At the inaugural Science Night training in 2015, elementary teachers expressed interest in starting a science night program at their school. Using TELA Science Night planning tools TEI staff and the TELA teacher leaders assembled a planning committee and successfully executed their first science night. The outcomes of the case study suggest the clarity of purpose of activities improved over the three-year case study and parental engagement with students at science nights also increased. Using the data, the TELA teachers wrote and received a grant to support future science nights. The two teachers have become science night trainers for the TELA, presenting workshops to plan a successful science night. The TEI staff and TELA teachers drafted a manuscript about the science night case study. This study has been published (Riggs et al., 2019) and is entitled, Engaging the Community through Science Nights: An Elementary School Case Study. The key outcomes of the case study were that Science Nights are successful in encouraging parent involvement in their child's STEM-related education along with strengthening the connection between teacher's and students' families. However, more research is still needed to define the role Science Nights play in encouraging STEM career exploration and awareness (Riggs et al., 2019).

The TEI and TELA teacher leaders hosted several grant writing trainings featuring materials created during summer programs. The training covered topics such as: identifying a specific aim or fundable idea, identifying the guidelines to writing a grant, describe editing tips for grant applications, and develop an outline for a grant application. Using a four-point Likert scale (anchored at 1: strongly disagree and 4: strongly agree), participating teacher responses indicated objectives were met (3.4), the training helped with teaching practices (3.3) and teacher expectations were met (3.5). Most participating teachers provided comments indicating the training provided them with new knowledge about the process of grant writing.

As proposed in the current SEPA award, teacher leaders and TEI staff created a grant writing training PowerPoint specifically designed for K-12 teachers. In the summer of 2019, the TELA leaders updated the training PowerPoint and made it into a narrated video training module available through the TEI website resources page. As of January 2020, the TELA resources page has accumulated 724-page views. The TEI has also posted a Grant Writing Support Request Form and are actively advertising its use to teachers. The TELA teacher leaders and TEI staff determined a need for individualized support for teachers through the grant writing process. The TELA Grant Writing Chair reviews grant writing support requests and provides constructive feedback to the inquiring teacher. Teachers typically submit grant applications for district and local foundation awards, like the Judson District Education Foundation, Walmart Foundation, and the Lowe's Foundation. As of March 2020, over \$54,000 in grant funding has been awarded to teachers who attended grant writing workshops since its inception. The following are examples of what the grants helped fund: yoga ball classroom seating to help energetic students stay engaged with lessons, electronic circuit kits that teach circuit concepts to lower grade levels, and playground equipment for one of the teacher's school.

The TEI utilized its robust list of collaborators to continue providing quality TPD training opportunities. These collaborators included UTHSA, Texas Biomed, the MSF, the City of San Antonio's Biomed SA, SA Works Foundations, the Alamo STEM Council, and the UTHSA Office of the Vice President of Research. The Spring Conferences continued throughout the duration of the current SEPA grant. The 2018 Spring Conference, attracted over 140 teachers and provided 35 in-depth TPD workshops. Some of the workshop topics were: "Middle School Teachers: Networking Through Collegial Conversations", "Life Lessons as an Immigrant Scientist", and "The Learning Lab: Zipping Towards STEM Careers". The 2019 Spring conference was held on February 2, 2019 and themed, Moving Beyond the Horizon. It featured a NASA Education Specialist as the keynote speaker and workshop presenter. Over $160 \mathrm{~K}-12$ teachers took part in a day long set of 26 workshops (35\% delivered by teachers). In addition, workshops were held for all three SEPA aims: peer mentoring, grant writing and science nights. The combined total of 32 teachers attended the workshops. Key outcomes of the conference include: increased attendance by area teachers $(7 \%)$, decreased "no show" rate $(18 \%$, down from 30\%), and over 1,000 Continuing Professional Education credits (CPEs) were awarded to teachers. Based on the grade levels taught by teachers in attendance, the estimated student impact is 17,024 local K-12 students. 


\section{The Value of Strong Partnerships and Lessons Learned.}

To increase the impact of the Spring Conference and ensure its future, the TEI worked diligently over the last year to establish a partnership with the Alamo STEM Ecosystem. The Alamo STEM Ecosystem is a countywide Community of Practice with a commitment to provide STEM/STEAM experiences for all students with a focus on students traditionally underrepresented in STEM/STEAM. The Alamo STEM Ecosystem acts to cultivate a STEM/STEAM mindset with a focus on equity and innovation in our community by aligning and connecting efforts with $18+$ committee members within the local education community. With this in mind, the Ecosystem was an ideal partner to take over control of the yearly annual Teacher Professional Development Spring Conference that the TEI led for the past 10 years. TEI worked with the Ecosystem to establish a structure for governance of the event. There was a committee as well as a chair and co-chair of the conference with the established expectation that the co-chair organization would learn and take on the responsibility of hosting and leading the conference the following year. The TEI served as chair for the 2020 Inaugural Alamo STEM Ecosystem Conference and trained the UTSA as the co-chair. The TEI had 47 workshops and 259 attendees, the largest to date.

Forming partnerships with other organizations and individuals are paramount to a teacher organization. Over the years, the TEI has fostered relationships with scientists and graduate trainees at UTHSCSA. These partnerships allowed for the development of our science-based teacher-authored curriculum and numerous associated TPD workshops. The TEI has also nurtured valuable partnerships with local institutions and organizations. Over the past decade the TEI has partnered with organizations that include but are not limited to Texas Biomed, Mind Science Foundation, BioMed SA, and Alamo STEM Ecosystem. These types of partnerships are invaluable to the TEI program and its teachers. They provide access to additional funding and support while providing TEI teachers firsthand experiences with real-world applications of scientific research.

TEI has also been able to build robust partnerships with districts and individual schools across San Antonio. These partnerships have allowed for the laying of the foundation for pilot projects and data collection to support subsequent SEPA awards. Additionally, these partners are now devoted to the future of TEI and our research endeavors.

Prompted by recommendations by the SEPA grant's external evaluators the TEI decided to discontinue the use of the STEBI and STAQ-R in early 2019. Due to issues with the evaluation design and recruitment strategy the use of the STEBI was halted. The STAQ-R was discontinued due to data collection challenges in the project's first two years. Most San Antonio area school districts would not provide the approval needed to use the STAQ-R in their teacher's classrooms, making student data unavailable. The external evaluators further recommended adopting assessments of a broader range of TELA outcomes, such as community-building, leadership, and teacher agency. The external evaluators are using a combination of quantitative surveys and qualitative interviews in order to offer a multifaceted view of teacher gains as a result of participation in TELA programs. Most school districts opted not to provide approval of the STAQ-R, making student data unavailable. Moving forward, evaluators will rely on teacher reports of improvements in their agency to make changes in their school and classroom. This will serve as an indicator of how teachers apply what they have learned in TEI programs so their practice and can be considered a predictor of student outcomes.

Recommendations for Next Steps. In the past the TEI has been reactionary in how it approached the direction of its program. In the next phase of its evolution the TEI is taking a proactive path to address the current gaps that hinder a teacher's ability to connect classroom science curriculum to real-world applications and STEM careers. Taking an innovative approach to teaching students traditional and nontraditional paths to a career in STEM will be a key component for the TEI moving forward. To provide our program with recommendations for next steps with the development of novel STEM career programs and to inform the aims and goals of our next SEPA program, we piloted innovative STEM Career curriculum activities our team and teacher leaders developed during the 2019 summer teacher program in partnership with Texas Biomedical Research STEM professionals. The STEM career curriculum was piloted in the fall of 2019 in one of the schools with whom we have built a strong partnership. This pilot allowed TEI to gain valuable feedback from teachers, students, and district leadership which shaped our next SEPA program.

To accomplish this our teacher leaders developed a STEM Career pilot pre-test to use in a sample group of students at the collaborating school. Based on the feedback from the student pilot pre-test survey and a teacher focus group held to gain additional teacher feedback, there was mounting evidence that many students are not aware of non-traditional STEM careers and opportunities. When the student participants identified STEM careers, they choose traditional STEM careers and left out many STEM careers that may be of interest to them and could align with their skills and talents. Further, they lacked awareness of San Antonio local STEM career opportunities. Likewise, they also chose traditional degrees and did not mention trade schools or non-traditional educational opportunities that may be more accessible and can serve as a stepping stone toward higher-level degrees. These gaps in awareness of nontraditional STEM career paths need to be filled and our STEM career curriculum is one innovative way to accomplish that goal. 
Through TEI's networking connections within the San Antonio community, TEI plans to actively seek additional partnerships in the clinical, military medical research, and biosciences startup community. These partnerships will expand our teacher's opportunities to engage directly with diverse local STEM professionals in a real-world environment, bringing teachers from the classroom into the various places where these companies and organizations reside. In this way, teachers can see research and research support careers firsthand. It is our goal to engage teachers in the process of evaluating these novel resources but will also facilitate the expansion of our STEM Careers curriculum and envisioned innovative programs.

\section{AUTHOR INFORMATION Corresponding Author}

Teresa M. Evans. evanstm@uthscsa.edu

\section{Author Contributions}

The manuscript was written through contributions of all authors. All authors have given approval to the final version of the manuscript.

\section{ACKNOWLEDGMENTS}

This K-12 teacher enrichment program was made possible through the work of the TEI staff members and the teacher-led Teacher Enrichment Leadership Academy, which believes that teachers are the frontline of our nation's future. We would like to thank the founding PI of this program, Michael J. Lichtenstein, MD, MSc and the founding EDS, Linda A. Pruski, MA, for their unwavering belief in the importance of empowering and supporting teachers. We also thank the amazing area teachers who work tirelessly and selflessly to provide our youth with relevant and up-to-date science education. Finally, we wish to thank the scientists at the University of Texas Health at San Antonio for volunteering their time and talent to support our teacher programs.

\section{FUNDING SOURCES}

This project was funded through the National Institutes of Health Science Education Partnership Award. Additionally, this program was supported by the NIGMS SEPA R25GM129182-03 awarded to T. Evans.

\section{ABBREVIATIONS}

AAAS: American Association for the Advancement of Science; C3: Coffee, Collegiality, and Collaboration; CAINE: Critical Appraisal to Improve Neuroscience Education; CPE: Continuing Professional Education; DAST:
Draw a Scientist Scale; IIMS: Integration of Medicine and Science; INQUIRE: Inquiring, Networking, Questioning, Understanding, Involving, Researching, Evolving; ISSS: Images of Science and Scientists Scale; MAX: Positively Aging: Maximizing the Healthspan; MSF: Mind Science Foundation; NA: National Academy; NCLB: No Child Left Behind; NCRR: National Center for Research Resources; NHLBI: National Heart, Lung, and Blood Institute; NIH: National Institutes of Health; OCD: Office of Career Development; SAI: Science Attitude Inventory; SNPRC: Southwest National Primate Research Center; STAAR: State of Texas Assessments of Academic Readiness; STAQ: Simpson Troost Attitudes Questionnaire; STAQ-R: Simpson Troost Attitudes Questionnaire-Revised; SETAKIST-R: Self-Efficacy Teaching and Knowledge Instrument for Science Teachers-Revised; South Central AHEC: South-Central Area Health Education Center; STEM: Science, Technology, Engineering, and Math; TAKS: Texas Assessment of Knowledge and Skills; TEA: Texas Education Agency; TEI: Teacher Enrichment Initiatives; TEKS: Texas Essential Knowledge and Skills; TELA: Teacher Enrichment Leadership Academy; Texas Biomed: Texas Biomedical Research Institute; TOSRA: Test of Science Related Attitudes; TPD: Teacher Professional Development; UTSA: University of Texas San Antonio; VBTA: Voelcker Biosciences Teacher Academy; WISS: Women in Science Scale; WISS-R: Women in Science Scale-Revised

\section{REFERENCES}

Blalock, C. L., Lichtenstein, M. J., Owen, S., Pruski, L., Marshall, C., and Toepperwein, M. (2008). In Pursuit of Validity: A comprehensive review of science attitude instruments 19352005. International Journal of Science Education, 30(7), 961-977. https://doi.org/10.1080/09500690701344578

Committee on Science, Engineering, And Public Policy (U.S. (2007). Rising above the Gathering Storm: energizing and employing America for a brighter economic future (pp. 2, 5). National Academies Press.

Drago-Severson, E. E., and Pinto, K. C. (2009). School leadership in support of teachers' learning: The dramatic differences that financial resources Make. Leadership and Policy in Schools, 8(4), 446-476. https://doi. org/10.1080/15700760802613661

Harrison, D. E., Strong, R., Sharp, Z. D., Nelson, J. F., Astle, C. M., Flurkey, K., Nadon, N. L., Wilkinson, J. E., Frenkel, K., Carter, C. S., Pahor, M., Javors, M. A., Fernandez, E., and Miller, R. A. (2009). Rapamycin fed late in life extends lifespan in genetically heterogeneous mice. Nature, 460(7253), 392-395. https://doi.org/10.1038/nature08221

Knepper, M. (2009). Shooting for the Moon: The Innocence of the No Child Left Behind Act's One Hundred Percent Proficiency Goal and Its Consequences Consequence. Saint Louis University Law Journal, 53(3), 901, 915. 
Ladd, H. F. (2017). No Child Left Behind: A Deeply Flawed Federal Policy. Journal of Policy Analysis and Management, 36(2), 461-469. https://doi.org/10.1002/pam.21978

Longo, C. (2010). Fostering creativity or teaching to the test? Implications of state testing on the delivery of science instruction. The Clearing House: A Journal of Educational Strategies, Issues and Ideas, 83(2), 54-57. https://doi. org/10.1080/00098650903505399

McCullers, J. F., and Bozeman, W. (2010). Principal self-efficacy: The effects of No Child Left Behind and Florida school grades. NASSP Bulletin, 94(1), 54. https://doi. org/10.1177/0192636510371976

McGuire, S. L. (1986). Promoting positive attitudes toward aging among children. Journal of School Health, 56(8), 322-324. https://doi.org/10.1111/j.1746-1561.1986.tb05762.x

McGuire, S. L. (1987). Aging education in schools. Journal of School Health, 57(5), 174-176. https://doi. org/10.1111/j.1746-1561.1987.tb00531.x

McGuire, S. L. (1994). Teaching young children about aging. Journal of Health Education, 25(2), 103-105. https://doi. org/10.1080/10556699.1994.10603011

Newman, A. B., Simonsick, E. M., Naydeck, B. L., Boudreau, R. M., Kritchevsky, S. B., Nevitt, M. C., Pahor, M., Satterfield, S., Brach, J. S., Studenski, S. A., and Harris, T. B. (2006). Association of long-distance corridor walk performance with mortality, cardiovascular disease, mobility limitation, and disability. JAMA, 295(17), 2018. https:// doi.org/10.1001/jama.295.17.2018

Pruski, L. A., Blanco, S. L., Riggs, R. A., Grimes, K. K., Fordtran, C. W., Barbola, G. M., Cornell, J. E., and Lichtenstein, M. J. (2013). Construct validation of the self-efficacy teaching and knowledge instrument for science teachers-revised (SETAKIST-R): Lessons learned. Journal of Science Teacher Education, 24(7), 1133-1156. https://doi. org/10.1007/s10972-013-9351-2

Pruski, L. A., Plaetke, R., Blalock, C. L., Marshall, C. E., and Lichtenstein, M. J. (2004). The Stealth Gerontology ${ }^{\mathrm{TM}}$ Program: Training teachers to infuse aging and age-related content into public school classrooms. Educational Gerontology, 30(8), 691-710. https://doi. org/10.1080/03601270490483913

Riggs, R. A., White, C. J., Kuenzi, T., Sifuentes, M., Garner, S. R., Gleason, R. A., Lee, J., Ziese, C. C., Berry, J., Garza, M. A., Vann, D., Fordtran, C. W., Grimes, K. K., Gray, J., and Evans, T. M. (2019). Engaging the community through science nights: An elementary school case study. The Journal of STEM Outreach, 2(1). https://doi.org/10.15695/jstem/ v2il.06

Stronge, J., and Hindman, J. (2003). Hiring the best teachers. Educational Leadership, 60(8), 48-52. http://www.ascd.org/ publications/educational-leadership/may03/vol60/num08/ toc.aspx
Whitney, C. R., and Candelaria, C. A. (2017). The effects of No Child Left Behind on children's socioemotional outcomes. AERA Open, 3(3), 1-21. https://doi. org/10.1177/2332858417726324 